\title{
PERFORMANCE EVALUATION OF AN INSURANCE COMPANY USING AN INTEGRATED BALANCED SCORECARD (BSC) AND BEST-WORST METHOD (BWM)
}

\section{Rishi Dwivedi 1, Kanika Prasad 2*, Nabankur Mandal 3, Shweta Singh 1, Mayank Vardhan ${ }^{1}$ and Dragan Pamucar ${ }^{4}$}

${ }^{1}$ Department of Finance, Xavier Institute of Social Service, Ranchi, India ${ }^{2}$ Department of Production and Industrial Engineering, National Institute of Technology, Jamshedpur, India

${ }^{3}$ Department of Mechanical Engineering, MCKV Institute of Engineering, West Bengal, India

${ }^{4}$ Department of Logistics, Military academy, University of Defence in Belgrade, Belgrade, Serbia

Received: 19 October 2020;

Accepted: 5 December 2020;

Available online: 13 December 2020.

Original scientific paper Abstract: Recent economy and financial business environment is undergoing a quick and accelerating revolution and paradigm shift, resulting in growing uncertainty and complexity. Therefore, the need for an all-inclusive and farreaching performance measurement model is universally felt as it can provide management-oriented information and act as a supporting tool in developing, inspecting, and interpreting policy-making strategies of an enterprise to achieve competitive advantages. Hence, this paper proposes an application of the balanced scorecard (BSC) model in an insurance organization for coordinating and regulating its corporate vision, mission, and strategy with organizational performance through the interrelation of different layers of business perspectives. In the next stage, a framework to unify both BSC and best-worst method (BWM) models is implemented for the very first time in the insurance domain to assess its performance over two-time periods. The integrated BSC-BWM model can help managers and decision-makers to figure out and interpret competing strength of the said enterprise and consecutively expedite inefficient and compelling decision making. Nevertheless, this integrated model is embraced and selected for a certain categorical business and there is enough future scope for its application to distinct industries.

\footnotetext{
* Corresponding author.

E-mail addresses: rishidwivedi12@yahoo.co.in (R. Dwivedi), kprasad.prod@nitjsr.ac.in (K. Prasad), nabankur2009@gmail.com (N. Mandal), shwetasinghaka12@gmail.com (S. Singh), mayank1293vardhan@gmail.com (M. Vardhan), dragan.pamucar@va.mod.gov.rs (D. Pamucar).
} 
R. Dwivedi et al./Decis. Mak. Appl. Manag. Eng. 4 (1) (2021) 33-50

Key words: Service sector, Insurance industry, BSC model, Best-Worst Method, BWM, Performance evaluation.

\section{Introduction}

Insurance is a contract or an agreement between an individual and a company, where the company pledges to pay an amount of sum assured to its customers against the insurance based on its terms and policies. The most significant reason for having insurance is that it provides security in many terms, to name a few: it generates financial resources, promotes economic growth, keeps commerce moving, ensures business and family stability, and encourages savings thereby securing future goals. A well-designed insurance plan helps in managing risks. In today's competitive world every company in the insurance sector tries hard to satisfy its customers. Every day the companies are introducing new plans and policies to attract new customers and retain their initial customer base.

The insurance sector plays a vital role in the development of the economy of any country. It is the only sector that garners long terms savings and generates funds for the development of the capital market and infrastructure, and hence providing stability to the growth of the economy. Besides, insurance is a vital component in carrying out smooth operational processes of national economies throughout the world. In developed countries, such as Germany, England, Switzerland, France, etc. insurance has become an important component of the economy as it contributes majorly to the global market. The Indian insurance sector has faced many stumbling blocks to attain its current position. Liberalization, privatization, and globalization (LPG) reforms in the year 1991 have played an important part in the development of this sector in India. Based on a report published by India Brand Equity Foundation in 2019 , the overall insurance industry in India is expected to reach US $\$ 280$ billion by 2020. The life insurance industry in the country is expected to grow by $12 \%$ to $15 \%$ annually for the next three to five years. Hence, the insurance sector is one of the booming sectors of the Indian economy.

Traditionally, the performance evaluation of an insurance organization's progress is carried out based on financial and customer factors only, which are mostly past indicators of success. The future drivers of progress for the enterprise are generally encompassed in the learning and growth and internal business perspectives of the balanced scorecard (BSC) model and are not taken into consideration in the traditional models of performance evaluation. BSC model considers both lagging and leading factors. The leading factors are also termed as futuristic parameters. They include the internal business perspective and the learning and growth perspective. The BSC model works with a holistic and integrated view of the business. It is a present-day performance measurement technique designed to overcome the drawback of traditional performance measurement systems. It is a performance measurement tool that consists of a set of measures that facilitates the enterprise's view of its overall performance. However, with time the BSC model has also been used as a strategic management tool as it can identify the key performance indicators (KPIs) of a company. In this paper, a BSC model is proposed for an insurance company operating in India while considering multiple factors such as profit after tax (PAT), operating profit ratio, asset under management (AUM), number of products, market share, etc. impacting the performance of the considered organization. Next, the best-worst method (BWM) is employed in this paper to solve the multi-criteria decision-making (MCDM) problem. According to the BWM technique, the best or the most important and the worst or the least important business performance evaluation criteria of an 34 
Performance evaluation of an insurance company using an integrated BSC and BWM insurance company are identified first by the decision-makers. Further, pair-wise comparisons are carried out for best to others identified criteria, and others chosen criteria to worst criterion. A maxi-min problem is then formulated and solved to determine the optimal weights of the different business performance parameters. A consistency ratio is estimated in the next step of BWM methodology to check and verify the reliability of the comparisons (Vesković et al., 2020). Furthermore, an integrated BSC-BWM structure is also designed in this paper to evaluate and appraise the progress of selected insurance enterprises over two time periods concerning key performance measures of the proposed BSC model to demonstrate the efficiency and effectiveness of management strategies applied. The results derived from the implementation of the above models would not only facilitate business performance measurement of the organization during a time period in quantitative terms but would also help the decision-makers to recognize what should be carried out and measured in an organization to reinforce and boost its productivity, performance, and progress. The results obtained from the application of the above model also contribute to the long term sustenance of the organization.

\section{Review of literature}

Rezaei (2015) proposed a new technique BWM to solve multi-criteria decisionmaking problems. Rezaei et al. (2016) developed a supplier selection model for food industry using the BWM tool. Ahmadi et al. (2017) employed BWM in manufacturing companies to analyze the social sustainability of their supply chains. Gupta (2018) applied hybrid BWM to identify the service quality parameters in the airline industry and then prioritized them based on customers' needs. Rezaei et al. (2018) developed a weighted logistics performance index based on the BWM method. Salimi and Rezaei (2018) proposed a multi-criteria decision-making method called BWM to calculate the weightage of research and development measures in small and medium-sized enterprises (SMEs). Zhao et al. (2018) and Kushwaha et al. (2020) implemented a hybrid framework on the basis of the BWM technique to assess the comprehensive benefit of eco-industrial parks in terms of circular economy and sustainability. Pamucar (2020) employed BWM for determining criteria weights in supply chain management.

Brunelli and Rezaei (2019) examined the BWM methodology for the MCDM problem from a more mathematical perspective. Kheybari et al. (2019) developed a BWM model for bioethanol facility location selection in provinces of Iran. Zolfani and Chatterjee (2019) not only investigated the weighting of important and related criteria for sustainable design but also evaluated the similarities and differences between the step-wise weight assessment ratio analysis (SWARA) and BWM techniques.

Chen et al. (2011) proposed an effective performance evaluation model based on the BSC technique which helped decision-makers to understand apt actions and achieve a competitive advantage. Mendes et al. (2012) applied the BSC model in the Urban Hygiene and Solid Waste Division of the Loulé Municipality in the south of Portugal. Pesic and Dahlgaard (2013) suggested that there were strong positive correlations between the BSC perspectives and European Foundation for Quality Management (EFQM) Excellence model criteria. Hakkak and Ghodsi (2014) concluded that the BSC model helped organizations in achieving sustainable competitive advantage. Staš et al. (2015) designed a conceptual framework for creating the Green Transport (GT) and BSC models from the viewpoint of industrial companies and supply chains using an appropriate MCDM method. Dwivedi and Chakraborty (2016) developed a BSC model for an Indian thermal power plant to help the organization to 
R. Dwivedi et al./Decis. Mak. Appl. Manag. Eng. 4 (1) (2021) 33-50

make strategic and tactical decisions. Anjomshoae et al. (2017) proposed a dynamic BSC model in the humanitarian supply chain. Dwivedi et al. (2018) designed a technique based on BSC for an Indian seed manufacturing organization to know about its performance so that the managers can align a company's operation with the existing business environment. Abdelghany and Abdel-Monem (2019) applied the BSC model that provided the utilities' managers with a fast but comprehensive view of the utilities' performance. Mohammadi et al. (2019) developed a feasibility test model for creative experiences based on the BSC technique through qualitative content analysis.

It can be comprehended from the ongoing literature review that earlier researchers have individually developed tools either by applying BSC or BWM for different real-world scenarios. The previous research works by past researchers have not consolidated BSC and BWM together. Thus, by applying the two methodologies together, this research work focuses on doing the performance evaluation of an insurance organization in India while understanding the leading and lagging parameters that contribute to the success and failure of the selected organization. Consequently, this integrated BSC and BWM model would fill the present gap for the real-time practical implementation of combined BSC as a BWM tool. This model would provide the latest perspective and motion for addressing real-world business performances and their assessment.

\section{BSC model}

Traditional performance measurement systems study and review the progress of an organization basically on the basis of a short-term financial objective. Those are no longer relevant to conquer the challenges faced by the organizations in recent times. Furthermore, with dynamic and growing business environment organizations have to make sure that their strategies are transformed into subsequent actions through a more meticulous and precise consideration of the objectives of related stakeholders. BSC model is often suggested and approved as an inclusive management tool linking critical strategic and short-term action planning (Kaplan, 1994; Badi et al., 2019). This technique is developed in such a way that it cancels the most typical and trivial mistake of the existing traditional systems of performance management, i.e. describing and reporting only on the basis of financial data. In today's cut-throat aggressive and competitive market, it is even more critical to attaining a balance between financial and non-financial data in management reporting and recording. Therefore, BSC is developed as a modern performance evaluation procedure to overcome the defect of the formerly adopted performance measurement systems through introducing four perspectives, i.e. financial perspective, customer perspective, internal perspective, and learning and growth perspective on which development and pace of an organization would be assessed. Financial and customer measures take into account the past performance of the organization and they are termed as lagging indicators. On the other hand, internal business process, and learning and growth perspective are leading indicators. Thus, a BSC model provides a holistic and integrated view of the business concerning four perspectives to the management. All the KPIs that are identified for the BSC model under each perspective must fit the sequence of cause and effect relationships within them.

\subsection{Designing of the BSC Model for an Insurance Sector Organization}

Developing a suitable BSC model for an enterprise needs a subtle evaluation of the organization's foundations, core values, beliefs, ideas, opportunities, financial 
Performance evaluation of an insurance company using an integrated BSC and BWM position, short-term and long-term goals, and operating business. The confidentiality of the studied organization is maintained here and hence, the name of the insurance enterprise is not being revealed and hereafter, it is referred to as ABC Limited. It is an organization that is growing at a rapid pace for a strong presence in the domestic insurance market. ABC Limited has exclusive, remarkable, and innovative insurance products that help it to compete in the market. All the data required for the development of a performance measurement tool based on the BSC model pertains to the financial years 2016-2017 and 2017-2018. Here, a focused group is selected constituting of subject experts to develop a BSC model for ABC Limited, while keeping a balanced representation of KPIs from each perspective. Figure 1 displays the developed BSC model for ABC Limited. It can be observed that the developed BSC model identified 20 business performance indicators that provide the management with a concise summary of the KPIs of $A B C$ Limited. These performance measures also assist in appropriately coordinating and regulating the business processes of $A B C$ Limited with its overall policy. Each identified performance parameter signifies a particular goal and competence of ABC Limited for all the four perspectives of the developed BSC model. For example, the key performance measure indicator of PAT suggests how much the organization really earns after paying interest and tax and how much it can utilize for its day to day business activities, whereas the operating profit ratio explains the profit a company generates after paying for variable costs of production, such as wages, raw materials, etc. The earning per share (EPS) is a critical and essential financial measure, which illustrates and reveals the profitability of a company. It is of utmost relevance and vital for people and investors trading in the stock market. EPS of a company is directly related to its profitability. On the other hand, gross written premium (GWP) is the total revenue from a contract expected to be received by an insurance company before deductions for reinsurance and ceding commissions. Moreover, average claim settlement time (in days), number of insurance products, number of branches, market share, and number of agents reveal the relationship of $\mathrm{ABC}$ Limited with its customers, which acts as a stimulant for its future growth. Further, the number of policies issued, AUM, number of employees, the amount spent on corporate social responsibility (CSR) activities, and numbers of transactions managed (in lakhs) are the internal performance measures that show the operational competence of $\mathrm{ABC}$ Limited to deliver its products and provide services consistently. Next, net promoter score (NPS), training expenses, transactions managed and policies issued within the turnaround time (TAT), management expenses, and employees' remuneration and welfare benefits represent the learning and growth aspect in the organization, which are of predominant importance for its long-term success while operating in a competitive insurance sector. Thus, the developed BSC model can expedite an effective monitoring of the organization's overall progress. This model successively helps the decision-makers in future strategy formulation. 
R. Dwivedi et al./Decis. Mak. Appl. Manag. Eng. 4 (1) (2021) 33-50

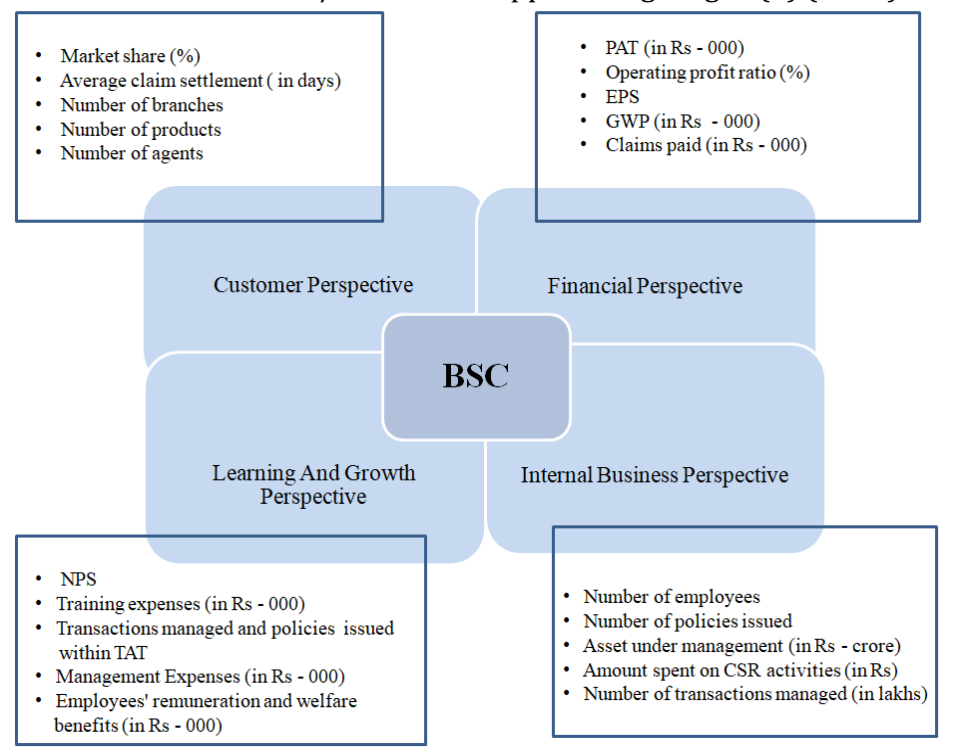

Figure 1: Developed BSC Model for ABC Limited

\section{BWM technique}

BWM is a multi-criteria decision-making (MCDM) tool developed to overcome the drawbacks of previously existent methods, like the analytical hierarchy process (AHP) in 2015 (Rezaei, 2015). BWM can be used in various decision-making fields, such as health, information technology, engineering, business, economics, and agriculture. In fundamental, wherever the objective is to rank and select a preference among a set of options, this method can be used. The pertinent features of BWM as compared to most current MCDM methods are that it requires fewer comparisons of data and leads to more dependable, steady, logical, and rational comparisons, which implies that the BWM model produces more decisive and stable results (Bozanic et al., 2020).

The BWM technique is employed to examine a set of alternatives with respect to some chosen criteria. It is based on a systematic pairwise comparison of the decision criteria, i.e. after identifying the decision criteria, two criteria are selected as the best decision criterion and the worst decision criterion by the decision-makers or experts. The best criterion is the one that has the most important and crucial role in making the decision, while the worst criterion has the opposite significance (Pamucar \& Ecer, 2020). The decision-makers then give their preferences of the best decision criterion over all the others and also their preferences of all the other criteria over the worst decision criterion using a number from a predefined scale of 1 to 9 . These two sets of pairwise comparisons and correlation are used as input for an optimization problem, the optimal results of which are the weights of the criteria. 
Performance evaluation of an insurance company using an integrated BSC and BWM

\section{Development of a business performance measurement tool for an insurance sector organization employing BSC and BWM tools}

The performance evaluation of an insurance company is dependent upon various factors. Here, the important drivers impacting the performance of selected insurance organization is already identified as the $20 \mathrm{KPIs}$ of the BSC model. Next, in order to determine the relative importance of selected KPIs, it is worthwhile to employ an MCDM method. Several MCDM methods have been applied in earlier studies for different selection problems. In this study, BWM is implemented for the evaluation of identified KPIs for the chosen insurance organization. This methodology has been successfully applied in several distinct real-world problems. Moreover, compared to other similar existing MCDM methods, BWM needs less pairwise comparison of data and the results achieved by it are more consistent.

\subsection{Steps in Implementation of BWM Technique}

The steps followed in BWM are as follows:

Step 1. Identify a set of evaluation criteria. In this step, a set of criteria $\left\{c_{1}, c_{2}\right.$, $\left.c_{3}, \ldots . . ., c_{n}\right\}$ is chosen for making a decision.

Step 2. The best criterion (most imperative or most important or most significant) and the worst criterion (least imperative or least important or least influential) are determined based on the decision-maker(s) or expert(s) opinion.

Step 3. The preference of the best decision criterion over all the other decision criteria is determined based on a score between 1 and 9 , where a score of 1 means equal preference between the best criterion and another criterion and a score of 9 means the extreme preference of the best criterion over the other criterion. The result of this step is the vector of best-to-others (BO) and is represented by vector $A_{B}$ :

$A_{B}=\left(a_{B 1}, a_{B 2}, a_{B 3}, \ldots . ., a_{B n}\right)$,

where $\mathrm{a}_{\mathrm{Bj}}$ indicates the preference of the best criterion $\mathrm{B}$ over criterion $\mathrm{j}$, and it can be deduced that $\mathrm{a}_{\mathrm{BB}}=1$.

Step 4. The preference of all the other decision criteria over the worst criterion is determined based on a score between 1 and 9 . The result of this step is the vector of others-to-worst (OW) and is indicated by vector $A_{w}$ :

$$
\boldsymbol{A}_{\boldsymbol{W}}=\left(a_{1 W}, a_{2 W}, a_{3 W}, \ldots \ldots \ldots \ldots . . . ., a_{n W}\right)^{T},
$$

where $a_{j w}$ shows the preference of the criterion $j$ over the worst criterion $W$. It also can be deduced that aww $=1$.

Step 5. The optimal weights $\left(w_{1}^{*}, w_{2}^{*}, w_{3}{ }^{*}, \ldots \ldots . . ., w_{n}{ }^{*}\right)$ are calculated. The optimal weight of the criteria satisfies the following requirements: For each pair of $w_{B} / w_{j}$ and $\mathrm{w}_{\mathrm{j}} / \mathrm{w}_{\mathrm{w}}$, the ideal situation is where $\mathrm{w}_{\mathrm{B}} / \mathrm{w}_{\mathrm{j}}=\mathrm{a}_{\mathrm{Bj}}$ and $\mathrm{w}_{\mathrm{j}} / \mathrm{w}_{\mathrm{w}}=\mathrm{ajw}_{\mathrm{w}}$. To satisfy these conditions for all $j$, a solution should be found where the maximum absolute differences $\left|\mathrm{w}_{\mathrm{B}} / \mathrm{w}_{\mathrm{J}}-\mathrm{a}_{\mathrm{B} \mathrm{j}}\right|\left|\frac{w B}{w_{j}}-a_{B j}\right|\left|\frac{w B}{w_{j}}-a_{B j}\right|$ and $\left|\mathrm{w}_{\mathrm{j}} / \mathrm{w}_{\mathrm{w}}-\mathrm{a}_{\mathrm{jw}}\right|$ for all $j$ is minimized. Considering the non-negativity and sum condition for the weights, the following problem is resulted: 
$\min x$

\section{Subject to,}

$$
\begin{aligned}
& \left|w_{B} / w_{J}-a_{B j}\right| \leq x, \text { For all } j, \\
& \left|w_{j} / w_{w}-a_{j w}\right| \leq x, \text { For all } j \\
& \sum w_{j}=1 \\
& w_{j} \geq 0, \text { for all } j
\end{aligned}
$$

After solving problem Equation (1), the optimal weights $\left(\mathrm{w}_{1}{ }^{*}, \mathrm{w}_{2}{ }^{*}, \mathrm{w}_{3}{ }^{*}, \ldots . . \mathrm{w}_{\mathrm{n}}{ }^{*}\right)$ and $\xi^{*}$ are obtained. $\xi^{*}$ can be seen as a direct indicator of the comparison system's consistency. The closer the value of $\xi^{*}$ is to zero, the higher the consistency, and, therefore, the more reliable and steadier the comparisons become.

\subsection{Application of the BWM in Insurance Organization}

Through the literature review and expert's view, 20 KPIs impacting the performance of the selected insurance enterprise under four perspectives of the BSC model is already identified in the previous section. Here in this research work, each perspective of the BSC model is treated as the main business performance criteria. Next, under all main business performance parameter for the chosen organization, five different KPIs are considered as sub-business performance criteria as shown in Table 1.

Table 1. Performance Criteria of ABC Limited

\begin{tabular}{cl}
\hline $\begin{array}{c}\text { Main business performance } \\
\text { criteria }\end{array}$ & Sub business performance criteria \\
\hline \multirow{3}{*}{ Customer perspective } & Market share (\%) \\
& Average claims settlement time (in days) \\
& Number of branches \\
& Number of products \\
& Number of agents \\
& PAT (in Rs - 000) \\
Financial perspective & Eperating profit ratio (\%) \\
& GWP (in Rs - 000) \\
& Claims paid (in Rs - 000) \\
& Number of employees \\
& Number of policies issued \\
Internal business perspective & AUM (in Rs - Crore) \\
& Amount spent on CSR activities (in Rs) \\
& Number of transactions managed (in Rs \\
& Lakhs) \\
& NPS \\
& Training expenses (in Rs - 000) \\
& Transactions managed and policies \\
Learning and growth & issued within TAT (\%) \\
perspective & Management expenses (in Rs - 000) \\
& Employees' remuneration and welfare \\
& benefits (in Rs - 000) \\
\hline &
\end{tabular}


Performance evaluation of an insurance company using an integrated BSC and BWM

After the four main business parameters and five sub-business performance criteria under each of those main parameters are listed, the next step is to estimate the relative weights of all sub-business performance parameters. This is carried out by first finding the global weights of four main business performance parameters. After that, the local weights of sub-business performance criteria under each main business parameter are computed. Final weights of each sub-business performance criteria are determined by utilizing Equation (2).

Final weight of sub business performance criteria $=$

Local weight of sub performance criteria $\times$

Global weight of main performance parameter

After carefully evaluating four main business performance parameters with respect to the identified organization's mission and operational constraints, the financial perspective is identified as the best criteria whereas the learning and growth perspective is selected as the worst one for $A B C$ Limited. The experts specified the preference of best criterion with respect to selected other main business performance criteria as shown in Table 2. Table 3 displays the other main business performance criteria's preference over the least important criterion.

Table 2. Preference of best criterion with respect to selected other main business performance criteria

\begin{tabular}{ccccc}
\hline $\begin{array}{c}\text { Best to } \\
\text { others }\end{array}$ & $\begin{array}{c}\text { Financial } \\
\text { perspective }\end{array}$ & $\begin{array}{c}\text { Customer } \\
\text { perspective }\end{array}$ & $\begin{array}{c}\text { Internal } \\
\text { Business } \\
\text { perspective }\end{array}$ & $\begin{array}{c}\text { Learning and } \\
\text { growth } \\
\text { perspective }\end{array}$ \\
\hline $\begin{array}{c}\text { Most } \\
\text { important : } \\
\text { Financial } \\
\text { perspective }\end{array}$ & 1 & 2 & 4 & 5 \\
\hline
\end{tabular}

Table 3. Other main business performance criteria's preference over the least important criterion

\begin{tabular}{lc}
\hline Others to the worst & Least important: \\
\hline Financial perspective & 5 \\
Customer perspective & 4 \\
Internal business perspective & 2 \\
Learning and growth perspective & 1 \\
\hline
\end{tabular}

Next, the optimal global weights of the main business performance criteria for $A B C$ Limited are calculated through solving Equation (1) while implementing the steps of the BWM technique as discussed in the earlier section. Table 4 shows the estimated global weights for all main business performance criteria with the consistency ratio (Zolfani et al., 2020). 
R. Dwivedi et al./Decis. Mak. Appl. Manag. Eng. 4 (1) (2021) 33-50

Table 4. Global weights for main business performance criteria

\begin{tabular}{cc}
\hline Main business performance criteria & Global weight \\
\hline Customer perspective & 0.2796 \\
Financial perspective & 0.4946 \\
Internal business perspective & 0.1398 \\
Learning and growth perspective & 0.0860 \\
Consistency ratio, $\xi^{*}$ & 0.0645 \\
\hline
\end{tabular}

It can be observed from Table 4 that the financial perspective has the highest weight of 0.4946 . The financial perspective's influence is the most critical and essential criterion when $\mathrm{ABC}$ Limited attempts to accomplish its mission and objectives. This is followed by the customer perspective and internal business perspective with weights of 0.2796 and 0.1398 respectively. The learning and growth perspective has the lowest criterion weight of 0.0860 showcasing its minimal relevance and importance in the comprehensive business growth of ABC Limited. The consistency ratio ( $\left.\xi^{*}\right)$ is close to zero, i.e. 0.0645 , which shows the high reliability and authenticity of the comparisons.

Furthermore, the sub-business performance criteria under the main business performance parameter of a financial perspective are examined to compute their local weights. Here, PAT is identified as the best sub-criterion whereas claims paid are selected as the worst one for $\mathrm{ABC}$ Limited. The best sub-criterion to other related subcriteria comparisons and others sub-criteria to worst sub-criterion comparisons of the financial perspective of $\mathrm{ABC}$ Limited is shown in Table 5 and Table 6.

Table 5. Preference of best sub-criterion of financial perspective with respect to other sub-business performance criteria of financial perspective

\begin{tabular}{cccccc}
\hline Best to others & PAT & $\begin{array}{c}\text { Operating } \\
\text { profit ratio }\end{array}$ & EPS & GWP & $\begin{array}{c}\text { Claims } \\
\text { Paid }\end{array}$ \\
\hline $\begin{array}{c}\text { Most important : } \\
\text { Profit after tax }\end{array}$ & 1 & 2 & 4 & 5 & 9 \\
\hline
\end{tabular}

Table 6. Other sub-business performance criteria's preference over the least important criterion of financial perspective

\begin{tabular}{cc}
\hline Others to the worst & Least important: Claims paid \\
\hline PAT & 9 \\
Operating profit ratio & 8 \\
EPS & 6 \\
GWP & 4 \\
Claims paid & 1 \\
\hline
\end{tabular}

Local weights for the five sub-business performance criteria under the main business performance parameter of financial perspective are estimated while following steps of BWM implementation as discussed in the earlier section and are displayed in Table 7. 
Performance evaluation of an insurance company using an integrated BSC and BWM

Table 7. Local weights for sub business performance criteria of financial perspective

\begin{tabular}{cc}
\hline Sub business performance criteria & Local weight \\
\hline PAT & 0.4457 \\
Operating profit ratio & 0.2713 \\
EPS & 0.1357 \\
GWP & 0.1085 \\
Claims paid & 0.0388 \\
Consistency ratio, $\xi^{*}$ & 0.0969 \\
\hline
\end{tabular}

It can be interpreted from Table 7 that PAT is the most crucial sub-business performance criteria under the financial perspective with a local weight of 0.4457 , followed by an operating profit ratio with the local weight of 0.2713 . Claims paid under financial perspective with a local weight of 0.0388 , is having minimal significance. The consistency ratio, $\xi^{*}$ for this particular estimation is 0.0969 showing its high consistency and reliability.

In a similar manner, the relative significance of sub-business performance criteria encompassed under the other three main business performance criteria, i.e. customer, learning and growth, and internal business perspectives are calculated as shown in Table 8.

Table 8. Local weights for sub business performance criteria of customer, learning, and growth, and internal business perspectives

\begin{tabular}{ccc}
\hline $\begin{array}{c}\text { Main business } \\
\text { performance criteria }\end{array}$ & Sub business performance criteria & $\begin{array}{c}\text { Local } \\
\text { weight }\end{array}$ \\
\hline Customer perspective & Market share & 0.4416 \\
& Average claims settlement time & 0.2589 \\
& Number of products & 0.1726 \\
Number of agents & 0.0863 \\
Internal business & Number of branches & 0.0406 \\
perspective & Consistency ratio, $\xi^{*}$ & 0.0761 \\
& AuM & 0.4615 \\
& Number of policies issued & 0.2706 \\
Number of employees & 0.1353 \\
Learning and growth & Amount spent on CSR activities & 0.0902 \\
perspective & Consistency ratio, $\xi^{*}$ & 0.0424 \\
& Nrans & 0.0796 \\
& Transactions managed & 0.4560 \\
& Training expenses & 0.2606 \\
& Employees' remuneration and welfare & 0.1042 \\
& benefits (Rs - 000) & 0.0489 \\
& Management expenses & 0.0651 \\
& Consistency ratio, $\xi^{*}$ & \\
& &
\end{tabular}


R. Dwivedi et al./Decis. Mak. Appl. Manag. Eng. 4 (1) (2021) 33-50

After the global weights for all four main business performance criteria and local weights of 20 sub business performance parameters are estimated, final weights of those sub-business performance criteria need to be estimated using Equation 2. For example, to estimate the final weight of PAT, its local weight, i.e. 0.4457 is multiplied with the global weight of main business performance criteria of financial perspective under which it falls, i.e. 0.4946. Thus, the final weight of the PAT is calculated as 0.2205 . The computed final weight of all sub-business performance criteria of ABC Limited is shown in Table 9.

Table 9. The final weight of all sub-business performance criteria of $\mathrm{ABC}$ Limited

\begin{tabular}{|c|c|c|c|c|}
\hline $\begin{array}{c}\text { Main } \\
\text { business } \\
\text { performance } \\
\text { criteria }\end{array}$ & $\begin{array}{l}\text { Global } \\
\text { weight } \\
\text { (i) }\end{array}$ & $\begin{array}{c}\text { Sub business performance } \\
\text { criteria }\end{array}$ & $\begin{array}{c}\text { Local } \\
\text { weight } \\
\text { (ii) }\end{array}$ & $\begin{array}{c}\text { Final } \\
\text { weight } \\
\text { (i) }{ }^{*} \\
\text { (ii) }\end{array}$ \\
\hline \multirow{5}{*}{$\begin{array}{l}\text { Customer } \\
\text { perspective }\end{array}$} & \multirow[t]{5}{*}{0.2796} & Market share & 0.4416 & 0.1235 \\
\hline & & Average claims settlement time & 0.2589 & 0.0724 \\
\hline & & Number of products & 0.1726 & 0.0483 \\
\hline & & Number of agents & 0.0863 & 0.0241 \\
\hline & & Number of branches & 0.0406 & 0.0114 \\
\hline \multirow{5}{*}{$\begin{array}{l}\text { Financial } \\
\text { perspective }\end{array}$} & \multirow[t]{5}{*}{0.4946} & PAT & 0.4457 & 0.2205 \\
\hline & & Operating profit ratio & 0.2713 & 0.1342 \\
\hline & & EPS & 0.1357 & 0.0671 \\
\hline & & GWP & 0.1085 & 0.0537 \\
\hline & & Claims paid & 0.0388 & 0.0192 \\
\hline \multirow{5}{*}{$\begin{array}{l}\text { Internal } \\
\text { business } \\
\text { perspective }\end{array}$} & \multirow[t]{5}{*}{0.1398} & AUM & 0.4615 & 0.0645 \\
\hline & & Number of policies issued & 0.2706 & 0.0378 \\
\hline & & Number of employees & 0.1353 & 0.0189 \\
\hline & & $\begin{array}{l}\text { Number of transactions } \\
\text { managed }\end{array}$ & 0.0902 & 0.0126 \\
\hline & & Amount spent on CSR activities & 0.0424 & 0.0059 \\
\hline \multirow{5}{*}{$\begin{array}{l}\text { Learning and } \\
\text { growth } \\
\text { perspective }\end{array}$} & \multirow[t]{5}{*}{0.0860} & NPS & 0.4560 & 0.0392 \\
\hline & & $\begin{array}{l}\text { Transactions managed and } \\
\text { policies issued within TAT }\end{array}$ & 0.2606 & 0.0224 \\
\hline & & Training expenses & 0.1303 & 0.0112 \\
\hline & & $\begin{array}{l}\text { Employees' remuneration and } \\
\text { welfare benefits }\end{array}$ & 0.1042 & 0.0090 \\
\hline & & Management expenses & 0.0489 & 0.0042 \\
\hline
\end{tabular}

\subsection{Designing a Performance Measure Index for ABC Limited}

After the comparative importance of all sub-business performance, criteria are determined for $\mathrm{ABC}$ Limited, an index is developed to assess the enterprise's overall business performance. To compute the performance measure index and examine the progress of $\mathrm{ABC}$ Limited concerning the performance evaluation parameters of the BSC model, the related data for all the 20 recognized sub-business performance criteria for two different time periods are required.

The first set of actual data related to the identified 20 performance measure indicators for the initial period is set as the baseline value, which in this case is derived from ABC Limited's annual report for the financial year 2016-17. Next, the current period value illustrates the second data set for those selected $20 \mathrm{KPIs}$ and is drawn 
Performance evaluation of an insurance company using an integrated BSC and BWM from the annual report of ABC Limited for the financial year 2017-18. An initial value of 100 is assigned to all sub-business performance criteria and afterward, their weighted points are calculated using Equation (3).

Weighted point $=$

Normalized performance measure weight $(N P M W) \times$ Initial point

Afterward, the business performance measure index for the initial period is estimated by taking the summation of all the initial period weighted points computed for each sub-business performance criteria. Table 10 shows a detailed computation of the performance measure index of ABC Limited for the initial period.

Table 10. The initial period performance index for ABC Limited

\begin{tabular}{|c|c|c|c|c|}
\hline $\begin{array}{c}\text { Sub business } \\
\text { performance criteria }\end{array}$ & $\begin{array}{l}\text { Baseline } \\
\text { value }\end{array}$ & NPMW & $\begin{array}{l}\text { Initial } \\
\text { point }\end{array}$ & $\begin{array}{c}\text { An initial } \\
\text { period } \\
\text { weighted } \\
\text { point }\end{array}$ \\
\hline PAT & 427973 & 0.2205 & 100 & 22.05 \\
\hline Operating profit ratio & 2 & 0.1342 & 100 & 13.42 \\
\hline Market share & 2 & 0.1235 & 100 & 12.35 \\
\hline $\begin{array}{l}\text { Average claims settlement } \\
\text { time }\end{array}$ & 46 & 0.0724 & 100 & 7.24 \\
\hline EPS & 0.97 & 0.0671 & 100 & 6.71 \\
\hline AUM & 2355 & 0.0645 & 100 & 6.45 \\
\hline GWP & 18426964 & 0.0537 & 100 & 5.37 \\
\hline Number of products & 114 & 0.0483 & 100 & 4.83 \\
\hline NPS & 26 & 0.0392 & 100 & 3.92 \\
\hline Number of policies issued & 1373056 & 0.0378 & 100 & 3.78 \\
\hline Number of agents & 6000 & 0.0241 & 100 & 2.41 \\
\hline $\begin{array}{l}\text { Transactions managed and } \\
\text { policies issued within TAT }\end{array}$ & 92 & 0.0224 & 100 & 2.24 \\
\hline Claims paid & 10131714 & 0.0192 & 100 & 1.92 \\
\hline Number of employees & 1702 & 0.0189 & 100 & 1.89 \\
\hline $\begin{array}{l}\text { Number of transactions } \\
\text { managed }\end{array}$ & 18 & 0.0126 & 100 & 1.26 \\
\hline Number of branches & 128 & 0.0114 & 100 & 1.14 \\
\hline Training expenses & 162191 & 0.0112 & 100 & 1.12 \\
\hline $\begin{array}{l}\text { Employees' remuneration } \\
\text { and welfare benefits }\end{array}$ & 1264666 & 0.0090 & 100 & 0.90 \\
\hline $\begin{array}{l}\text { Amount spent on CSR } \\
\text { activities }\end{array}$ & 1109000 & 0.0059 & 100 & 0.59 \\
\hline Management Expenses & 4646140 & 0.0042 & 100 & 0.42 \\
\hline Performance index & - & - & - & 100 \\
\hline
\end{tabular}

To inspect and analyze the growth and advancement of the organization over the considered period, the performance measure index for the consequent period is also needed. So, the first step in calculating the performance measure index for the current year is to calculate the current period points by the following equations. Equation (4) 
R. Dwivedi et al./Decis. Mak. Appl. Manag. Eng. 4 (1) (2021) 33-50

and Equation (5) are employed for beneficial and non-beneficial performance parameters respectively.

Current period point $=($ Current year value / Baseline value $) \times 100$

Current period point $=$

$200-[($ Current year value / Baseline value $) \times 100]$

Applying Equation (6), the value of the current period weighted point for the individual sub-business performance parameter is now similarly estimated.

Weighted point $=$

Normalized performance measure weight $(N P M W) \times$ Initial point

Next, the performance index for the current period is calculated by adding up all the current period weighted points for all the individual sub-business performance measures. The comprehensive estimation of the current period index for $\mathrm{ABC}$ Limited is shown in Table 11.

A judgment of the performance measure index values for the current period with those for the initial period, derived from Table 10 and Table 11 respectively, helps in assessing and understanding the comprehensive business performance of $A B C$ Limited over the two different time periods and thus allowing the policymakers to understand the effectiveness of various applied policies. It can be noticed that ABC Limited has significantly improved its performance measure index to 129.98 for the current period in comparison to 100 for the initial period. This implies that the said enterprise is advancing in an appropriate direction to its organizational objectives, vision, and mission. Furthermore, a comparison of the current period weighted point with that of initial period weighted point values for individual sub-business performance criteria suggests ABC Limited's progression over two time periods with respect to that particular criteria. It can be observed that $A B C$ Limited has significant enhancement and development in current period weighted point of PAT, operating profit ratio, AUM, number of products, NPS, number of policies issued, number of agents, and number of transactions managed with respect to their corresponding values in initial period weighted point. The standard operating procedures of the organization to achieve this advancement in the said criteria should be maintained in the future also. Besides, it can also be noticed that although the organization is progressing in the right direction, there is some sub-business performance parameter on which $\mathrm{ABC}$ Limited is not advancing in the correct preposition. The sub-business performance criteria on which ABC Limited is not performing well are market share, average claims settlement time, EPS, transaction managed and policies issued within TAT, training expenses, number of branches and employees' remuneration and welfare benefits. These identified parameters are the area where the resources need to be deployed by the management of $A B C$ Limited in order to convert them from nonperforming criteria to performing criteria in the future. This can help the organization in achieving long term sustenance. 
Performance evaluation of an insurance company using an integrated BSC and BWM

Table 11. Performance index for current period for ABC Limited

\begin{tabular}{|c|c|c|c|}
\hline $\begin{array}{c}\text { Sub-business } \\
\text { performance criteria }\end{array}$ & $\begin{array}{c}\text { Current } \\
\text { period value }\end{array}$ & $\begin{array}{c}\text { Current } \\
\text { period point }\end{array}$ & $\begin{array}{l}\text { Current period } \\
\text { weighted point }\end{array}$ \\
\hline PAT & 786281 & 183.72 & 40.51 \\
\hline Operating profit ratio & 3 & 150.00 & 20.13 \\
\hline Market share & 1.65 & 98.21 & 12.13 \\
\hline $\begin{array}{c}\text { Average claims settlement } \\
\text { time }\end{array}$ & 50 & 91.30 & 6.61 \\
\hline EPS & 0.57 & 58.76 & 3.94 \\
\hline AUM & 2992 & 127.05 & 8.20 \\
\hline GWP & 19507884 & 105.87 & 5.68 \\
\hline Number of products & 130 & 114.04 & 5.50 \\
\hline NPS & 40.5 & 155.77 & 6.11 \\
\hline Number of policies issued & 2012574 & 146.58 & 5.54 \\
\hline Number of agents & 7500 & 125.00 & 3.02 \\
\hline $\begin{array}{c}\text { Transactions managed } \\
\text { and policies issued within } \\
\text { TAT }\end{array}$ & 90.4 & 97.94 & 2.20 \\
\hline Claims paid & 9221366 & 108.99 & 2.09 \\
\hline Number of employees & 1769 & 103.94 & 1.97 \\
\hline $\begin{array}{c}\text { Number of transactions } \\
\text { managed }\end{array}$ & 29 & 161.11 & 2.03 \\
\hline Number of branches & 127 & 99.22 & 1.13 \\
\hline Training expenses & 203982 & 74.23 & 0.83 \\
\hline $\begin{array}{l}\text { Employees' remuneration } \\
\text { and welfare benefits }\end{array}$ & 1351988 & 93.10 & 0.83 \\
\hline $\begin{array}{l}\text { Amount spent on CSR } \\
\text { activities }\end{array}$ & 2104468 & 189.76 & 1.13 \\
\hline Management Expenses & 4650523 & 99.91 & 0.42 \\
\hline Performance index & - & - & 129.98 \\
\hline
\end{tabular}

\section{Conclusion}

The insurance sector is one leading sector for corporate houses for business operation. The proposed model is inclusive of both lagging factors and leading factors related to the business performance for an insurance sector organization. The integrated BSC and BWM technique is a comprehensive and broad model for realworld insurance sector application. Through this study, it can be comprehended that a combined BSC-BWM model can be successfully applied to design a quantitative tool to measure the business performance of an organization and monitor the efficiency and effectiveness of the implemented strategies, which may drive the pathway for future policymaking. In this combined model both past (lagging) and futuristic (leading) parameters are taken into account with two different periods. This provided better analysis and scrutiny of business operating data to the management of an organization. The management can take corrective action to enhance the business potential if there is a significant deviation from the desired and expected business performance of the organization.

There is enormous competition among insurance sector organizations to enhance their profit margin, market share, and customer base while minimizing operating 
R. Dwivedi et al./Decis. Mak. Appl. Manag. Eng. 4 (1) (2021) 33-50

expenses and developing and launching new insurance products that are widely accepted by customers. In this paper, a BSC model is first developed for an insurance sector enterprise in India to identify a relevant range of financial and non-financial parameters that supports effective and impressive business management. Next, a business performance measurement tool combining BSC and BWM methods is developed and applied in the said organization to exhibit how it can be engaged to monitor the performance of the firm, which can be finally utilized as a driver for the organization's future growth. This unified BSC and BWM model can also be employed by other organizations of different sectors with minor adjustments. It requires time and attention while defining the KPIs for the insurance sector which is a limitation of the proposed work.

Author Contributions: Each author has participated and contributed sufficiently to take public responsibility for appropriate portions of the content.

Funding: This research received no external funding.

Conflicts of Interest: The authors declare no conflicts of interest.

\section{References}

Abdelghany, M., \& Abdel-Monem, M. (2019). Balanced scorecard model for water utilities in Egypt. Water Practice and Technology, 14(1), 203-216.

Ahmadi, H. B., Kusi-Sarpong, S., \& Rezaei, J. (2017). Assessing the social sustainability of supply chains using Best Worst Method. Resources, Conservation and Recycling, 126, 99-106.

Andjelkovic Pesic, M., \& Dahlgaard, J. J. (2013). Using the Balanced Scorecard and the European Foundation for Quality Management Excellence model as a combined roadmap for diagnosing and attaining excellence. Total Quality Management \& Business Excellence, 24(5-6), 652-663.

Anjomshoae, A., Hassan, A., Kunz, N., Wong, K. Y., \& de Leeuw, S. (2017). Toward a dynamic balanced scorecard model for humanitarian relief organizations' performance management. Journal of Humanitarian Logistics and Supply Chain Management, 7(2), 194-218.

Badi, I., Shetwan, A., \& Hemeda, A. (2019). A grey-based assessment model to evaluate health-care waste treatment alternatives in Libya. Operational Research in Engineering Sciences: Theory and Applications, 2(3), 92-106.

Bozanic, D., Tešić, D., \& Milić, A. (2020). Multicriteria decision making model with Znumbers based on FUCOM and MABAC model. Decision Making: Applications in Management and Engineering, 3(2), 19-36.

Brunelli, M., \& Rezaei, J. (2019). A multiplicative best-worst method for multi-criteria decision making. Operations Research Letters, 47(1), 12-15.

Chen, F. H., Hsu, T. S., \& Tzeng, G. H. (2011). A balanced scorecard approach to establish a performance evaluation and relationship model for hot spring hotels based on a hybrid MCDM model combining DEMATEL and ANP. International Journal of Hospitality Management, 30(4), 908-932. 
Performance evaluation of an insurance company using an integrated BSC and BWM Dwivedi, R., \& Chakraborty, S. (2016). Development of a strategic management tool in a thermal power plant using ABC and BSC models. Serbian Journal of Management, 11(1), 81-97.

Dwivedi, R., Chakraborty, S., Sinha, A. K., \& Singh, S. (2018, June). Development of a performance measurement tool for an agricultural enterprise using BSC and QFD models. In IOP Conference Series: Materials Science and Engineering (Vol. 377, No. 1, p. 012214). IOP Publishing.

Gupta, H. (2018). Evaluating service quality of airline industry using hybrid best worst method and VIKOR. Journal of Air Transport Management, 68, 35-47.

Hakkak, M., \& Ghodsi, M. (2015). Development of a sustainable competitive advantage model based on balanced scorecard. International Journal of Asian Social Science, 5(5), 298-308.

Kaplan, R. S. (1994). Devising a balanced scorecard matched to business strategy. Planning Review, 22(5), 15-48.

Kheybari, S., Kazemi, M., \& Rezaei, J. (2019). Bioethanol facility location selection using best-worst method. Applied energy, 242, 612-623.

Kushwaha, D. K., Panchal, D., \& Sachdeva, A. (2020). Risk analysis of cutting system under intuitionistic fuzzy environment. Reports in Mechanical Engineering, 1(1), 162 173.

Mendes, P., Santos, A. C., Perna, F., \& Teixeira, M. R. (2012). The balanced scorecard as an integrated model applied to the Portuguese public service: a case study in the waste sector. Journal of Cleaner Production, 24, 20-29.

Mohammadi, A., Moharrer, M., \& Babakhanifard, M. S. (2019). The business model and balanced scorecard in creative tourism: the ultimate strategy boosters. Current Issues in Tourism, 22(17), 2157-2182.

Pamucar, D. (2020). Normalized weighted Geometric Dombi Bonferoni Mean Operator with interval grey numbers: Application in multicriteria decision making. Reports in Mechanical Engineering, 1(1), 44-52.

Pamucar, D., \& Ecer, F. (2020). Prioritizing the weights of the evaluation criteria under fuzziness: The fuzzy full consistency method - FUCOM-F. Facta Universitatis, series: Mechanical Engineering. 18(3), 419 - 437.

Rezaei, J. (2015). Best-worst multi-criteria decision-making method. Omega, 53, 4957.

Rezaei, J., Nispeling, T., Sarkis, J., \& Tavasszy, L. (2016). A supplier selection life cycle approach integrating traditional and environmental criteria using the best worst method. Journal of Cleaner Production, 135, 577-588.

Rezaei, J., van Roekel, W. S., \& Tavasszy, L. (2018). Measuring the relative importance of the logistics performance index indicators using Best Worst Method. Transport Policy, 68, 158-169.

Salimi, N., \& Rezaei, J. (2018). Evaluating firms' R\&D performance using best worst method. Evaluation and program planning, 66, 147-155. 
R. Dwivedi et al./Decis. Mak. Appl. Manag. Eng. 4 (1) (2021) 33-50

Staš, D., Lenort, R., Wicher, P., \& Holman, D. (2015). Green transport balanced scorecard model with analytic network process support. Sustainability, 7(11), 1524315261.

Vesković, S., Milinković, S., Abramović, B., \& Ljubaj, I. (2020). Determining criteria significance in selecting reach stackers by applying the fuzzy PIPRECIA method. Operational Research in Engineering Sciences: Theory and Applications, 3(1), 72-88.

Zhao, H., Guo, S., \& Zhao, H. (2018). Comprehensive benefit evaluation of eco-industrial parks by employing the best-worst method based on circular economy and sustainability. Environment, development and sustainability, 20(3), 1229-1253.

Zolfani, S. H., \& Chatterjee, P. (2019). Comparative evaluation of sustainable design based on Step-wise Weight Assessment Ratio Analysis (SWARA) and best worst method (BWM) methods: a perspective on household furnishing materials. Symmetry, 11(1), 74.

Zolfani, S.F., Yazdani, M., Pamucar, D., \& Zarate, P. (2020). A VIKOR and TOPSIS focused reanalysis of the MADM methods based on logarithmic normalization. Facta Universitatis, series: Mechanical Engineering. 18(3), 341-355. 